Article

\title{
Development of Eco-Friendly and Self-Cleaning Lime-Pozzolan Plasters for Bio-Construction and Cultural Heritage
}

\author{
Federica Fernandez ${ }^{1, *}$, Silvia Germinario ${ }^{1,2}$, Roberta Basile ${ }^{1}$, Roberta Montagno ${ }^{1}$, \\ Kali Kapetanaki ${ }^{3}$, Konstantinos Gobakis ${ }^{3}$, Dionysia Kolokotsa ${ }^{4}{ }^{\circ}$, Anna Maria Lagou ${ }^{3}{ }^{\circ}$, \\ Panagiota Dania $^{3}$, Maria Teresa Enna ${ }^{5}$, Maria Mangiapane ${ }^{5}$ and Pagona-Noni Maravelaki ${ }^{3, *(D)}$ \\ 1 Department of Nanotechnologies and Innovative Materials, Istituto Euro Mediterraneo di Scienza e \\ Tecnologia, 20-90139 Palermo, Italy; silvia.germinario@uniba.it (S.G.); robertabasile@iemest.eu (R.B.); \\ robertamontagno@iemest.eu (R.M.) \\ 2 Department of Earth and Geo-environmental Sciences, University of Bari Aldo Moro, 70126 Bari, Italy \\ 3 Laboratory of Materials for Cultural Heritage and Modern Building, School of Architecture, \\ Technical University of Crete, 73100 Chania, Greece; kapetanaki.kali@gmail.com (K.K.); \\ kgobakis@isc.tuc.gr (K.G.); annamarialagou@hotmail.com (A.M.L.); dania.panagiota@gmail.com (P.D.) \\ 4 Laboratory of Energy Management in the Built Environment, School of Environmental Engineering, \\ Technical University of Crete, 73100 Chania, Greece; dkolokotsa@enveng.tuc.gr \\ 5 Department of Renewable Energy, Resource Efficiency and Aerospace Research, Istituto Euro Mediterraneo \\ di Scienza e Tecnologia, 20-90139 Palermo, Italy; ing.mariateresaenna@gmail.com (M.T.E.); \\ mariamangiapane@gmail.com (M.M.) \\ * Correspondence: federicafernandez@iemest.eu (F.F.); pmaravelaki@isc.tuc.gr (P.-N.M.)
}

Received: 14 July 2020; Accepted: 22 September 2020; Published: 28 September 2020

check for updates

\begin{abstract}
Nowadays, the design and use of multi-functional mortars has increased significantly, with interesting applications in the green building and cultural heritage conservation sectors. A key point for a correct adoption of these innovative materials is their behavior along time and their resistance to the weathering. The objective of this project was to define the performance and durability of innovative mortars, in order to use them correctly and to avoid irreparable damage over time. For the development of this project, lime-metakaolin and hydraulic lime-metakaolin based mortars (hereinafter called A, B), as well as $\mathrm{A}$ and $\mathrm{B}$ with the addition of nano- $\mathrm{TiO}_{2}$ and perlite (hereinafter referred to as $\mathrm{A}+, \mathrm{B}+$ ), have been tested. The focus of the work was to carry out preliminary tests to evaluate the performance and durability characteristics of these mortars, verifying their behavior over time through exposure to artificial aging cycles, including thermal shock cycles in saline solution aerosols, freeze cycles in vapor aerosol, and aging by heat treatment at high temperatures. Before and after each artificial aging cycle, weight measurements, and macroscopic and microscopic observations were performed in order to evaluate possible structural changes. The characteristics of the mortars were assessed by determination of the apparent volume mass, mechanical properties, such as compressive and bending strength, water absorption, whereas their self-cleaning capacity was measured by methylene blue degradation test under UV and solar irradiation. The results obtained show degradation effects in the mortar samples due to aging after each test, and indicated that mortars with perlite and nano- $\mathrm{TiO}_{2}$ are the best-performing ones, both from the durability and energetic point of view, rendering them suitable for applications in the green building sector and the conservation of cultural heritage.
\end{abstract}

Keywords: energy efficient mortars; photocatalytic; cultural heritage; bio architecture; nano-titanium dioxide; artificial ageing; self-cleaning 


\section{Introduction}

Green building (also known as green construction or sustainable building) refers to a structure and using process that is environmentally responsible and resource-efficient throughout a building's life-cycle: from sitting to design, construction, operation, maintenance, renovation, and demolition [1]. Sustainable buildings require the use of materials with advanced performances, meeting the need to minimize waste and reduce energy consumption. Nowadays, great attention is paid to the external surfaces of buildings for which new materials with performances, such as greater thermal insulation, good resistance to dirt, and depolluting functions, have emerged [2].

A key points of these new materials is their longer life, or durability along time, in order to minimize the need for renovations and, therefore, reduce the environmental impact of disposal [3]. One of the major durability problems of external plasters is related to the impact of atmospheric agents onto the surface of the building, with particular reference to the various forms of water that affect the porous structure of the materials. Incomplete understanding of the causes and degradation mechanisms of the exposed material have frequently led to the application on buildings of conservation products that have subsequently been proven harmful for protection and sustainability, fundamental requirements for applications on green building of cultural heritage.

The degradation of buildings often begins on its external surface due to the continuous interaction between materials and the surrounding environment [4]. The susceptibility and durability of the construction materials to decay depends on the intrinsic characteristics of the materials and the different climatic conditions the urban fabric is subjected.

One of the possible causes related to the degradation of stone materials is the crystallization of the salts that form crystals upon precipitation from the liquid circulated into the pores of the stone [5-11]. In particular, as Barbera et al. 2012 [12] have shown, the evolution of a saturated saline solution that impregnated the pores of the material in conditions of high wind circulation and temperature is the subsequent salt crystallization in the interior parts from the surface. The growth of the crystals is linked to the crystallization pressure, which is inversely proportional to the average pore radius and increases with the interface tension. Other authors have shown that temperature variation is one of the main factors influencing the properties and physical integrity of stone materials. The thermal conductivity of the rocks is directly related to its consistency and, in general, increases with the decrease in porosity [13-19].

Furthermore, several studies have shown that the action of frequent thermal shocks in extreme temperature conditions is one of the main causes of degradation of the construction materials located both in historic and modern buildings $[16,19,20]$. An additional agent that causes severe deterioration to architectural surfaces is the increasing air pollution. Atmospheric pollutants deposited on surfaces are responsible for the erosion, recession, and crust formation on building and monumental materials. In order to handle this challenge, advanced consolidants and innovative plasters based on nanotechnology have been developed [21-23]. More specifically, during the last years, many studies have investigated the photocatalytic activity of $\mathrm{TiO}_{2}$ in the field of new construction technologies and for cultural heritage preservation [24-29].

Recent laboratory results showed that all the $\mathrm{TiO}_{2}$ mortars exhibited good photocatalytic efficiency. Moreover, it was demonstrated that photocatalytic mortars can be applied in case of new construction, as well as in old buildings, because the nanoadditives do not compromise the mortar hardened state properties [30].

Nowadays, although various $\mathrm{TiO}_{2}$-functionalized building products are already commercially available, a full appraisal of their long-term performance in use conditions is still missing and their performances along time are not verified. Only a few studies in the literature go beyond their self-cleaning efficiency in laboratory condition, or the measurement of the photodegradation of a specific pollutant, and actually propose a long-term approach to this issue [31-33].

Maury Ramirez et al. showed that, after aging, the ability of $\mathrm{TiO}_{2}$ coatings to remove $\mathrm{NOx}$ from air and their self-cleaning ability decreased compared with the initial performance [33]. 
The loss of $\mathrm{TiO}_{2}$ efficiency was associated to natural aging after outdoor exposure, especially in the case of coatings subjected to climatic conditions [34]. Environmental stress may also cause particles detachment and thickness reduction of the coating, owing to the degradation of the coating binder and its consequent detachments, as well as a partial deactivation due to the adsorption of pollutants or reaction products of the photocatalytic processes [35].

Recent studies demonstrated also that self-cleaning and photocatalytic materials have the added value of a potential prolonged maintaining of their optical performance in spite of soot and particulate matter deposition [34], and of mitigating atmospheric pollution [35].

Regarding the influence of nanoTiO ${ }_{2}$ on mechanical properties, researches have proved that the quantity added is critical, as different addition of the optimum amount could cause a decrease in mechanical strengths due to agglomeration $[29,30]$.

With all these premises, the objective of this project was to develop of innovative mortars, to be used in the green building as well as in the conservation of cultural heritage, being realized without the use of cement, a not environmental friendly material and not compatible with the historic ones. Moreover, the self-cleaning properties will contribute to more durable/lower maintenance building façades (plastering and finishing) by limiting attack from microorganisms and pollutants.

Summarizing, the requirements sought for the new mortars were: absence of cement, good mechanical resistance, low water absorption, low thermal conductivity in order to contribute to the improvement of the energy performance of the building, self-cleaning capacity, good durability over time, and resistance to salts.

The project, through specific laboratory tests and aging cycles, defines the performance and durability of the developed mortars in order to use them correctly and to avoid irreparable damage over time.

\section{Materials and Methods}

For the development of this research project, lime-based mortars with binder of pure hydrated lime (L; by CaO Hellas, Dalkafoukis, Thessaloniki, Greece) and hydrated lime with addition of natural hydraulic lime (NHL; NHL3.5z by Lafarge, Clamart, France), hereinafter called A, B, respectively, both enriched with a natural pozzolan (Poz; bio-pozzolana produced by Cimmino Calci based in Casoria, Italy) and an artificial one (metakaolin: Mt MetaStar 501 by Imerys, France) were synthesized. In addition, in $\mathrm{A}$ and $\mathrm{B}$ mortars, inclusions of nano- $\mathrm{TiO}_{2}$ (nano-structured nano-titania by NanoPhos, Lavrion, Greece) and perlite (Peralit 13 of the Italian Perlite with a nominal fine particle size $0.1-1 \mathrm{~mm}$ ) were introduced (hereinafter referred to as $\mathrm{A}+, \mathrm{B}+$ ). Regarding the nature of aggregates, natural calcium carbonate sand derived from limestone rocks of sedimentary origin, reference was made to the manufacturer Marmifera Mineraria based in Trapani, Italy. This is a waste produced by stone processing, inert, which can be disposed of in a 2nd category landfill. The particle size used is category G81, from 500 to 1100 microns, hardness 3-4 Mhos, white color content in $\mathrm{CaCO}_{3}$ not less than $99.24 \%$. The mix design of the synthesized mortars is presented in Table 1.

Table 1. Mortars mix design.

\begin{tabular}{|c|c|c|c|c|c|c|c|c|c|c|}
\hline \multirow{2}{*}{ Code } & \multicolumn{4}{|c|}{ Binder wt.\% } & \multirow{2}{*}{$\begin{array}{l}\mathrm{TiO}_{2} \\
\text { wt. } \%\end{array}$} & \multirow{2}{*}{$\begin{array}{l}\text { Perlite } \\
\text { wt. } \%\end{array}$} & \multirow{2}{*}{$\begin{array}{l}\text { Carbonaceous } \\
\text { Sand wt.\% }\end{array}$} & \multirow{2}{*}{$\mathbf{B} / \mathbf{A}^{*}$} & \multirow{2}{*}{$\mathbf{W} / \mathbf{B}^{*}$} & \multirow{2}{*}{$\begin{array}{c}\text { Consistency } \\
\text { (mm) }\end{array}$} \\
\hline & NHL $^{*}$ & $\mathbf{L}^{*}$ & Poz $^{*}$ & $\mathbf{M t}^{*}$ & & & & & & \\
\hline $\mathrm{A}$ & & 20 & 6.7 & 6.7 & & - & 66.7 & $1 / 2$ & $0.8( \pm 0.21)$ & 133.5 \\
\hline $\mathrm{A}+$ & & 19.4 & 6.5 & 6.5 & 1.6 & 1.6 & 64.5 & $1 / 2$ & $0.8( \pm 0.23)$ & 128.3 \\
\hline $\mathrm{B}$ & 10 & 10 & 6.7 & 6.7 & & & 66.7 & $1 / 2$ & $0.8( \pm 0.19)$ & 134.7 \\
\hline $\mathrm{B}+$ & 9.7 & 9.7 & 6.5 & 6.5 & 1.6 & 1.6 & 64.5 & $1 / 2$ & $0.7( \pm 0.07)$ & 149.3 \\
\hline
\end{tabular}

* NHL: natural hydraulic lime, L: lime, Poz: natural pozzolan, Mt: metakaolin, $\mathrm{TiO}_{2}$ : nano- $\mathrm{TiO}_{2}, \mathrm{~B} / \mathrm{A}$ : binder to aggregates ratio, W/B: water to binder ratio, consistency measured by flow table test.

In the first phase, an adequate number of specimens of specific size have been produced with the use of all the different mix design, as follows: 
- $\quad 16 \times 4 \times 4 \mathrm{~cm}$ for mechanical test;

- $\quad 4 \times 4 \times 4 \mathrm{~cm}$ for water vapor permeability and aging tests;

- $\quad 9 \times 9 \times 3 \mathrm{~cm}$ for solar reflectance and infrared emittance tests;

- $\quad 20 \times 20 \times 2 \mathrm{~cm}$ for thermal conductivity test.

For each type of mortar, and each type of experiment, at least 3 specimens were used.

After a suitable seasoning (28 days), the specimens were characterized from the physical-mechanical and energetic point of view. More specifically, the following tests have been performed:

The apparent density of the hardened mortar samples was determined from the ratio of the dry mass $\mathrm{M}_{\mathrm{O}}$ to the total volume occupied by the solid (including porosity) [35].

Water absorption tests were carried out after immersing the samples in water according to the specifications of the UNI EN 12087 [36], before and after artificial aging. Furthermore, the water vapor permeability of the mortars was measured according to the UNI EN 15803 [37].

The photocatalytic degradation of the organic components, through the oxidation reaction of active radicals generated by the activation of nano- $-\mathrm{TiO}_{2}$ with $\mathrm{UV}$ and solar radiation, was examined using methylene blue in aqueous solution as the contrast liquid.

The energy efficiency of the designed mortars was assessed by measuring the solar reflectance, the infrared emittance and the thermal conductivity. The solar reflectance was measured in the UV-VIS-NIR spectrum using a Cary 5000 spectrophotometer fitted with a $150 \mathrm{~mm}$ diameter integrating sphere (Labsphere DRA 2500, Agilent, Waldbronn, Germany) that combines specular and diffuse radiation. The reference reflectance standard used for the measurement is constructed with Spectralon ${ }^{\circledR}$ (Labsphere, Agilent, Waldbronn, Germany). The spectral reflectance measurements were performed following the ASTM E903-96 "Standard test method for solar absorptance, reflectance, and transmittance of material using integrating spheres" [38] in conjunction with ASTM E891 air mass 1.5 beam normal spectrum "Standard Test Method for Solar Absorptance, Reflectance, and Transmittance of Materials". The characteristics of the Cary 5000 with integrating spheres are: Resolution of $200-2500 \mathrm{~nm}$ and accuracy of $\pm 0.02 \mathrm{~nm}$. The infrared emittance measurements were performed using the Devices and Services AE1 emissometer (Devices and Services Dallas, Dallas, TX, USA). The procedure used is described in the Devices \& Services Technical Note TN10-2. The characteristics of the AE1 emissometer are: Resolution of $0.04-0.93$, accuracy of \pm 0.01 and repeatability of \pm 0.01 emittance units. The thermal conductivity was measured using a Hot Disk TSP1500, Gothenburg, Sweden fitted with a $14.6 \mathrm{~mm}$ (radius) Kapton-insulated sensor. The measurements were performed following the ISO 22007-2 in room temperature. The characteristics of the Hot Disk TSP1500 are: $0.01-400 \mathrm{~W} /(\mathrm{mK})$, accuracy better than $5 \%$ and reproducibility better than $1 \%$.

The mechanical assessment of the designed mortars was evaluated by uniaxial compression and the three points bending test using a stiff $1600 \mathrm{kN}$ MTS hydraulic testing frame (model 815) (MTS, Eden Prairie, MN, USA) [39]. Compressive and flexural strength, modulus of elasticity, and toughness were determined by the above-mentioned tests.

In order to evaluate the durability of mortars, selected samples were subjected to different cycles of artificial aging using a Memmert M30-750 (Schwabach, Germany) and a freezer Angelantoni Lifescience Ekobasic EKOBASIC 700/1BT (Bernareggio, Italy) to evaluate possible modifications upon exposure to thermo-hygrometric stress conditions. The first test included accelerated aging employing thermal shocks in aerosol saline solution $\left(9 \mathrm{~g}\right.$ of $\mathrm{NaCl} / 1 \mathrm{~L}$ of $\mathrm{H}_{2} \mathrm{O}$ ) that allowed evaluating the potential structural changes of the mortars to sudden temperature changes. The samples were cyclically subjected to an aerosol phase with saline solution $(2 \mathrm{~h})$ and a subsequent phase in an oven at $60^{\circ} \mathrm{C}(3 \mathrm{~h})$ for a total of 10 cycles. The second aging test is related to freezing and thawing processes; in particular all the types of mortar were subjected to an aerosol phase with steam $(2 \mathrm{~h})$ and a frost phase in the freezer at $-20^{\circ} \mathrm{C}(3 \mathrm{~h})$, for a total of 10 cycles. The third aging test involved heat treatment at high temperatures, consisting of 10 alternating heating cycles at $60^{\circ} \mathrm{C}(12 \mathrm{~h})$ and $100{ }^{\circ} \mathrm{C}(12 \mathrm{~h})$. The fourth and fifth series of aging tests were performed to better understand and evaluate the resistance of mortars to thermal shocks $\left(-20^{\circ} \mathrm{C} /+80^{\circ} \mathrm{C}\right)$ and the performance to aggressive environments, such as immersion in water 
and exposure to salt mist vapor. The five different defined accelerated aging protocols (I, II, III, IV, V) for the mortars under study are presented in Table 2:

Table 2. Accelerated aging protocols.

\begin{tabular}{|c|c|c|c|}
\hline \multicolumn{3}{|c|}{ Aging Protocol } & \multirow{3}{*}{$\begin{array}{c}\text { Aging Process } \\
\text { Salt fog steam }(9 \mathrm{~g} / \mathrm{L}) \\
\text { Heat Treatment }+60^{\circ} \mathrm{C}\end{array}$} \\
\hline & 2 series (1 cycle) & $2 \mathrm{~h}$ & \\
\hline 1 & \& series (1 cycle) & $3 \mathrm{~h}$ & \\
\hline \multirow{2}{*}{ II } & \multirow{2}{*}{2 series ( 1 cycle) } & $2 \mathrm{~h}$ & Steam \\
\hline & & $3 \mathrm{~h}$ & Heat Treatment $-20^{\circ} \mathrm{C}$ \\
\hline \multirow{2}{*}{ III } & \multirow{2}{*}{1 series ( 1 cycle) } & $12 \mathrm{~h}$ & Heat Treatment $+60^{\circ} \mathrm{C}$ \\
\hline & & $12 \mathrm{~h}$ & Heat Treatment $+100^{\circ} \mathrm{C}$ \\
\hline \multirow{4}{*}{ IV } & \multirow{4}{*}{1 series ( 1 cycle) } & $1 \mathrm{~h}$ & Immersion in \\
\hline & & & demineralized water \\
\hline & & $3 \mathrm{~h}$ & Heat Treatment $-20^{\circ} \mathrm{C}$ \\
\hline & & $6 \mathrm{~h}$ & Heat Treatment $+60^{\circ} \mathrm{C}$ \\
\hline \multirow{3}{*}{$\mathrm{V}$} & \multirow{3}{*}{1 series ( 1 cycle) } & $1 \mathrm{~h}$ & Salt fog steam $(9 \mathrm{~g} / \mathrm{L})$ \\
\hline & & $3 \mathrm{~h}$ & Heat Treatment $-20^{\circ} \mathrm{C}$ \\
\hline & & $6 \mathrm{~h}$ & Heat Treatment $+80^{\circ} \mathrm{C}$ \\
\hline
\end{tabular}

\section{Results}

\subsection{Apparent Density}

With reference to the determination of the average apparent density, the results obtained for the four types of mortars can be considered in line with other plasters used in the restoration of monuments. Similarly, the apparent density of the samples that underwent the accelerated aging cycles exhibited a slight decrease in the average density, as can be appreciated in Table 3. This can be explained by the discontinuities and damage induced in the sample microstructure after aging. However, it should be emphasized that the low decrease of $1-2 \%$ in apparent density after aging evidenced the durability of the designed mortars. The performance of samples with perlite and nano- $\mathrm{TiO}_{2}$, namely $\mathrm{A}+$ and $\mathrm{B}+$, is superior, compared to the corresponding ones without those additives. This finding can be related to the specific microstructure after the additive's incorporation that resisted better to the freeze-thaw cycles. The porous structure of perlite decreased the mortars apparent density, but enabled the mortar to resist better to aging due to the space available for the salt crystallization.

Table 3. Apparent density before and after aging.

\begin{tabular}{|c|c|c|}
\hline Type of Sample & Apparent $\varrho\left(\mathrm{Kg} / \mathrm{m}^{3}\right)$ before Aging & Apparent $\varrho\left(\mathrm{Kg} / \mathrm{m}^{3}\right)$ after Aging \\
\hline Mortar A & 1812.23 & 1783.11 \\
\hline Mortar A+ & 1761.25 & 1745.06 \\
\hline Mortar B & 1772.42 & 1745.63 \\
\hline Mortar B+ & 1725.37 & 1706.44 \\
\hline
\end{tabular}

\subsection{Water Absorption by Total Immersion}

The results for the total immersion absorption tests, performed before and after aging tests, were presented in Figures 1 and 2, respectively, showing similar imbibition coefficient either for mortars $\mathrm{A}$ and $\mathrm{B}$ without additives (imbibition coefficient $\approx 9$ ) or for mortars $\mathrm{A}+$ and $\mathrm{B}+$ with perlite and nano-TiO ${ }_{2}$ (imbibition coefficient $\approx 11$ ). This behavior could be attributed to the hydrophilic capacity of nano- $\mathrm{TiO}_{2}$ and perlite, which is also reflected to the water absorption of $\mathrm{A}+$ and $\mathrm{B}+$ mortars. Perlite exhibit this tendency in increasing water absorption due to the voids in its structure, while nano- $-\mathrm{TiO}_{2}$ is a very hydrophilic material $[40,41]$. The rate of the water absorbed by the various samples showed an almost equal behavior for all the specimens that were examined. All of the types of mortars exhibited 
a rapid increase in the amount of water absorbed in the first 5-10 min, whereas the test ended after 35 min as the mass was stabilized.

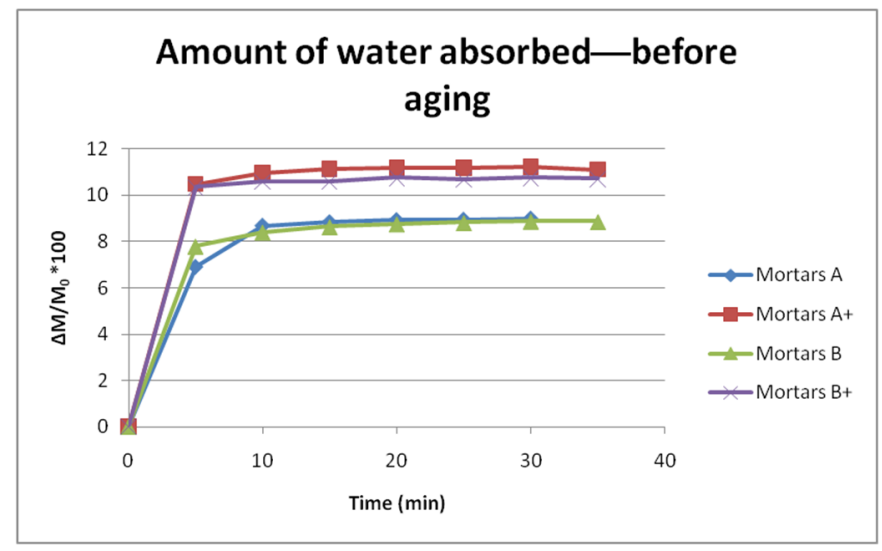

Figure 1. Water absorbed for the designed mortars before aging.

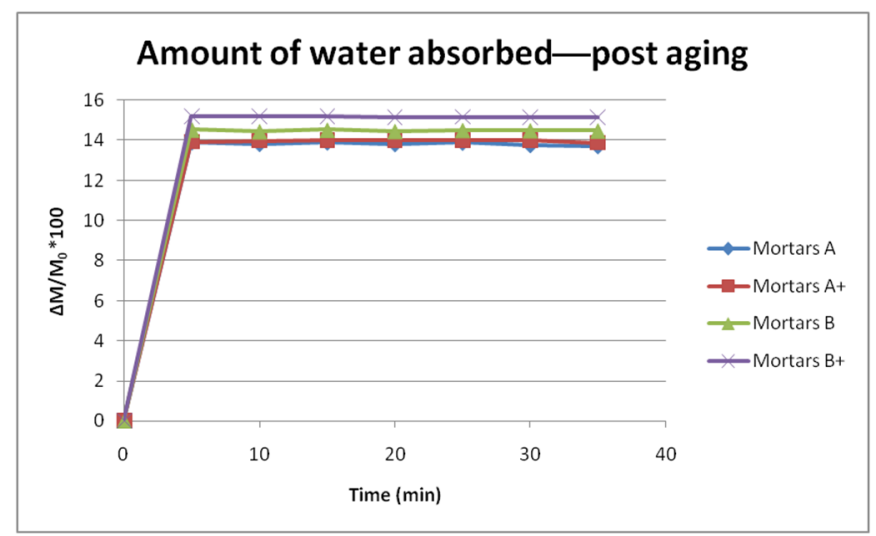

Figure 2. Water absorbed for the designed mortars after aging.

Under similar conditions and with a similar procedure, the test was repeated for the same mortar samples after aging. Similarly, to the pre-aged samples, the experiment ended after $35 \mathrm{~min}$ as a stabilization of the weight of the samples was recorded. However, observing the data, there is an increase in the imbibition capacity for all types of mortar compared to the pre-aging values. The greatest increases are found for mortar B $(+64 \%)$ and mortar A $(+53 \%)$. For the B+ mortar an increase of $+42 \%$ is noticed, being the A+ mortar the sample with the lowest water absorption after aging $(+25 \%)$. The decrease in CI after aging in the samples with additives is in close relationship with the lower decrease in the apparent density above-mentioned.

\subsection{Water Vapor Permeability}

The water vapor permeability of the designed mortars is presented in Figure 3. Mortars containing natural hydraulic lime (B) seem to be more compact, as they allow the water vapor to be escaped in a lower quantity and rate from their matrix. Furthermore, the addition of perlite plays a key role in the increase of porosity and, as a consequence, in the permeability of the mortars [42]. This positive contribution of perlite in the water vapor escape is clearly expressed in Figure 3 with the increasing slope of B+ curve. The lower water vapor permeability of the B mortars corroborated the lower amount of water absorbed due to the compactness of mortars with natural hydraulic lime. Furthermore, from the values of transpiration capacity of A and A+ mortars, it can be further confirmed the important role played the binder hydrated lime. 


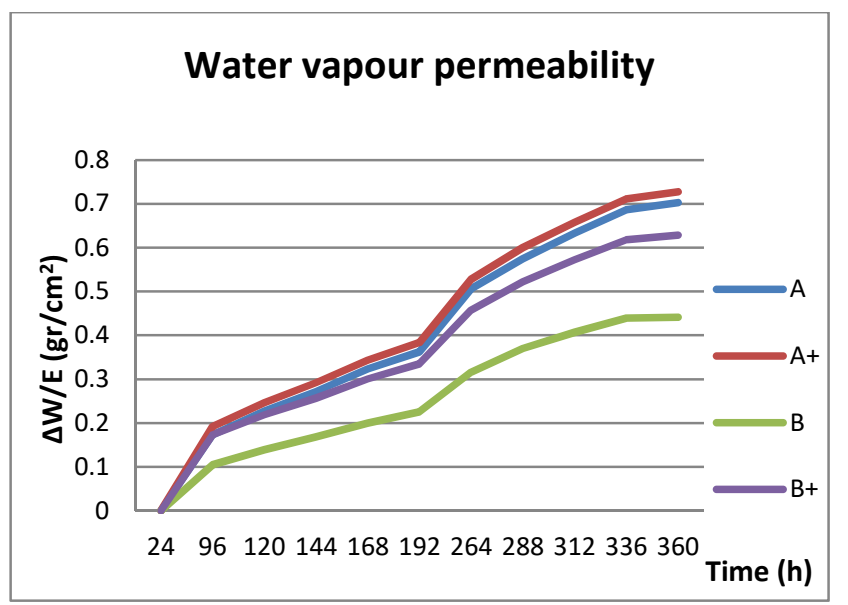

Figure 3. Water vapor permeability curves.

\subsection{Photocatalytic Activity}

Regarding the evaluation of the photocatalytic activity, the results obtained in Figures 4 and 5 showed a discoloration of the methylene blue after one week of irradiation under UV lamp; the discoloration is more evident on the samples subjected to solar radiation.

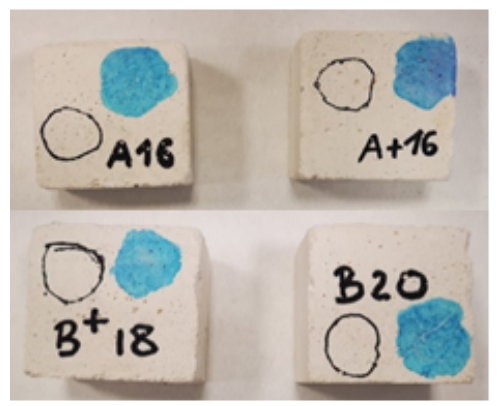

(a)

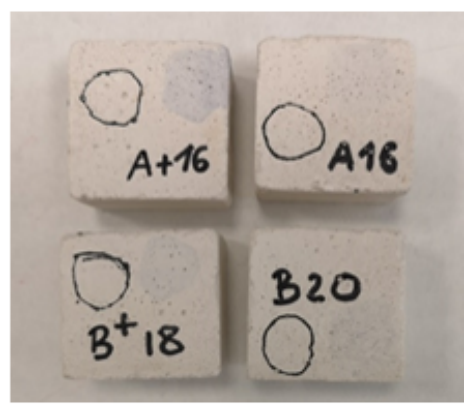

(b)

Figure 4. Methylene blue discoloration: samples (a) before and (b) after 1-week exposure to UV rays.

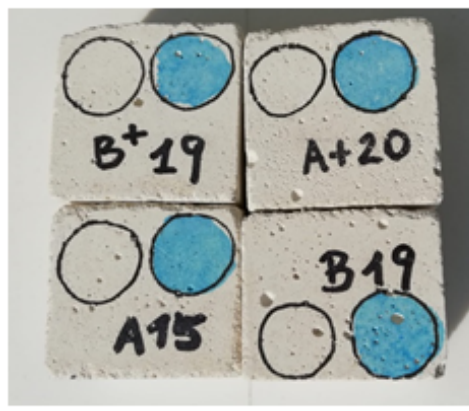

(a)

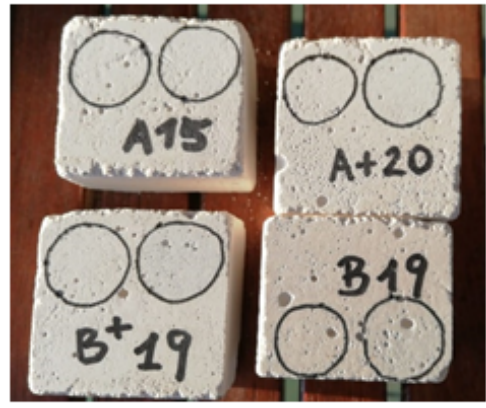

(b)

Figure 5. Methylene blue discoloration: (a) before and (b) after 1-week exposure to solar radiation.

\subsection{Energy Efficiency Evaluation}

The reflectance in the near-infrared (NIR), the ultraviolet (UV), and the visible wavelengths, as well as the infrared emittance and the thermal conductivity of the tested mortars, are presented in Table 4. All of the syntheses exhibited very promising performance as the total reflectance and the infrared emittance are favorably compared to specific plasters and coatings proposed as agents that contributed to the reduction of the surface temperature of conventional renders in architectural 
surfaces [43-47]. More specifically, the mortars with perlite and nano- $\mathrm{TiO}_{2}$ exhibited lower reflectance in the ultraviolet range due to the addition of the latter, which has a large absorption in UV range. The thermal conductivity is significantly lower than traditional plasters containing cements with $\lambda$ $=0.53 \mathrm{~W} /(\mathrm{mK})$ and other commercial plasters such as Latemar ${ }^{\circledR}$ plaster with $\lambda=0.61 \mathrm{~W} /(\mathrm{mK})$ [47]. These results are remarkable, as thermal conductivity plays a key role at the thermal insulation of external building surfaces. Furthermore, as expected, mortars with perlite, such as A+ and B+ were characterized by lower values of thermal conductivity compared to the corresponding ones without perlite, due of lightweight perlite [47].

Table 4. Reflectance, infrared emittance (IE), and thermal conductivity $(\lambda)$ of the designed mortars*

\begin{tabular}{ccccccc}
\hline Synthesis & SR (\%) & SR $_{\text {NIR }}(\mathbf{\%})$ & SR $_{\text {VIS }}(\mathbf{\%})$ & SR $_{\text {UV }}(\mathbf{\%})$ & IE & $\lambda \mathbf{W} /(\mathbf{m K})$ \\
\hline A & 80.9 & 80.9 & 76.25 & 47.11 & 0.89 & 0.32 \\
A+ & 73.1 & 76.15 & 71.05 & 30.10 & 0.92 & 0.29 \\
B & 79.64 & 81.04 & 79.73 & 54.82 & 0.91 & 0.32 \\
B+ & 75.99 & 78.76 & 74.13 & 37.37 & 0.90 & 0.28 \\
\hline
\end{tabular}

* SR (\%)-Total reflectance; $\mathrm{SR}_{\mathrm{NIR}}(\%)$ reflectance in near-IR range; $\mathrm{SR}_{\mathrm{VIS}}(\%)$ reflectance in visible range; $\mathrm{SR}_{\mathrm{UV}}(\%)$ reflectance in UV range.

\subsection{Mechanical Properties}

The average values, as well as the standard deviation of the compression test, namely, compression strength, modulus of elasticity, and toughness, along with the bending strength extracted from the three-point bending test, are presented in Figure 6. The designed mortars A and B exhibited mechanical properties, such as compressive and bending strength, which could be favorably compared to the corresponding values of the conventional cement mortars. The addition of perlite and nano- $\mathrm{TiO}_{2}$ decreased the resistance of mortars to compressive and bending strength, as well as the modulus of elasticity and the toughness. As far as the mechanical properties are concerned, the addition of both perlite and nano- $\mathrm{TiO}_{2}$ resulted in a worst performance of the studied materials. However, the application of designed mortars as plasters for external building surfaces does not require high mechanical strengths. Furthermore, the compressive strength of $A+$ and $B+$ mortars are more promising compared to the respective ones of other lime mortars with admixtures and additions entailed to replace cement $[47,48]$.
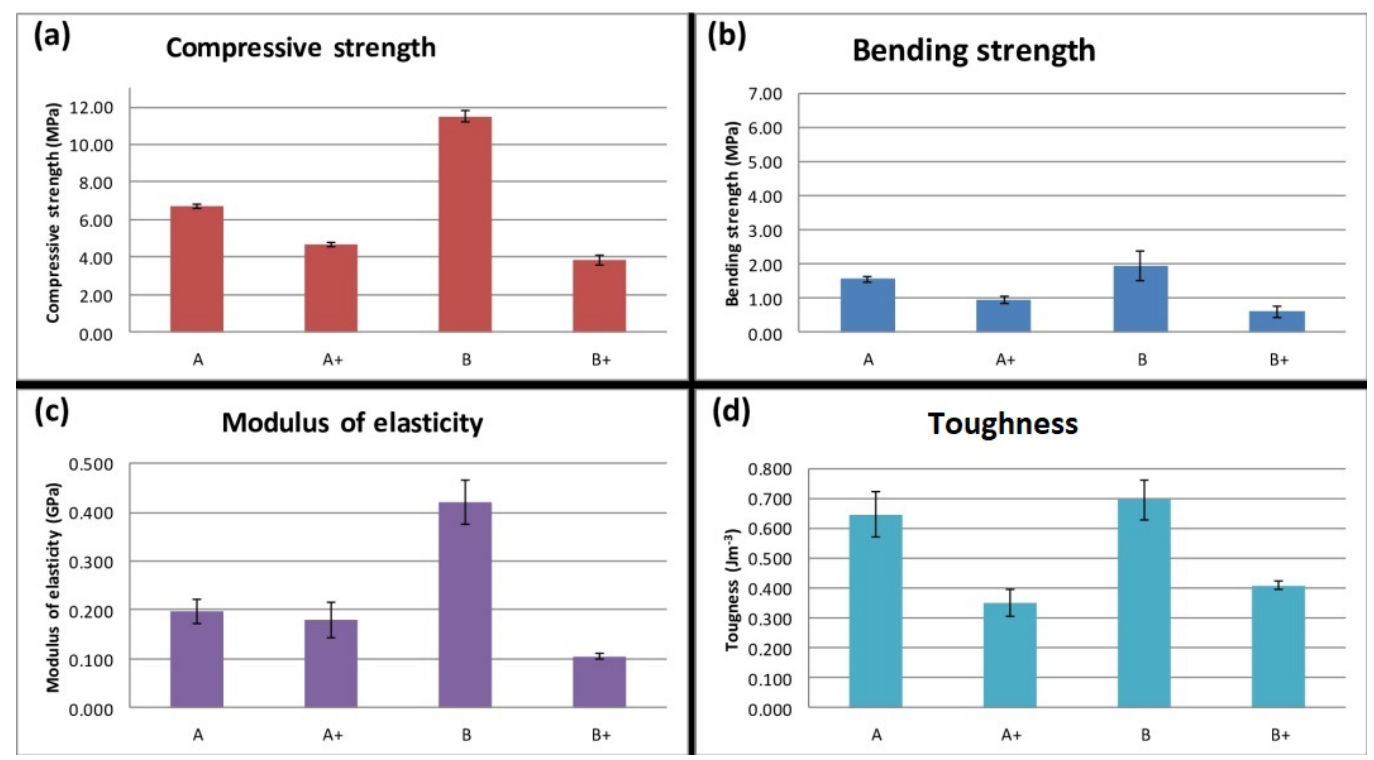

Figure 6. (a) Compressive strength, (b) bending strength, (c) modulus of elasticity, and (d) toughness of the designed mortars in 28 days. 


\subsection{Durability of Mortars}

The experimental approach of the accelerated aging procedures that were adopted and supported by measuring specific physical parameters, has been proven decisive in order to approach the durability of mortars in a holistic way. The main goal of the aging tests conducted on the samples was to simulate as closely as possible the natural aging that occurs in the original mortars under environmental loading. The samples showed signs of degradation due to aging after each test. In particular, the results obtained after aging with the first three accelerated aging protocols (I, II, III) show that, macroscopically, the samples did not preserve their shape and external aspect, showing evident signs of deterioration. Only A+ type shows a lower mass loss percentage, Figure 7.

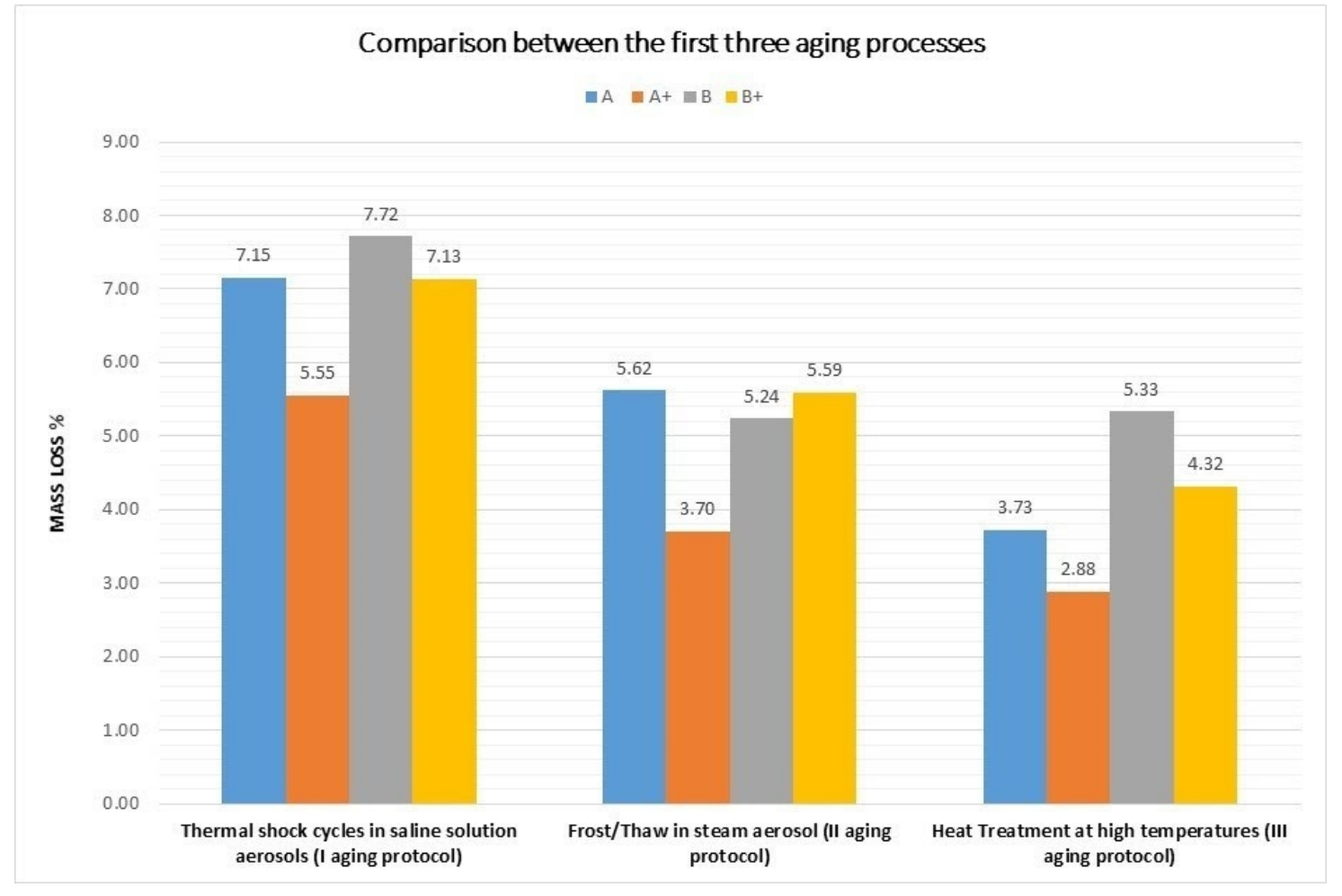

Figure 7. Comparison of aging protocols.

In regards to the fourth protocol (immersion in demineralized water), the results show $\mathrm{B}+$ as the best performing mix design, while for the other types of mortar $(\mathrm{A}, \mathrm{A}+, \mathrm{B})$, from the fourth cycle, evident exfoliation and fracturing were noticed, leading, in some cases, to the total detachment of a superficial layer.

The fifth protocol (salt fog steam) confirmed the results obtained from the previous aging protocols, indicating $\mathrm{A}+$ and $\mathrm{B}+$ as the best-performing mortars.

\section{Conclusions}

The activities and tests carried out have made it possible to test mortar samples with a different mix design, with or without nano- $\mathrm{TiO}_{2}$ and perlite. In particular, the results obtained from the apparent density and water vapor permeability tests can be considered in line with the properties of other plasters, normally used in the restoration of monuments. The discoloration of the methylene blue under UV lamp evidenced the photocatalytic activity of all the produced mortar samples. Furthermore, all of the samples showed promising energetic performance, especially in the cases of samples with nano- $-\mathrm{TiO}_{2}$. Only the mechanical performance of the samples with nano- $\mathrm{TiO}_{2}$ and perlite was registered as lower compared to corresponding samples without those additives. As opposed to that, the results obtained after the artificial aging of mortars with hydraulic lime and metakaolin- mixed with nano- $\mathrm{TiO}_{2}$ 
and perlite (i.e., $\mathrm{A}+$ and $\mathrm{B}+$ types) were rather interesting, and confirmed a considerable durability. This is because the samples showed the lower mass loss percentage after all the tests, even in presence of aggressive environments with marine aerosol. It is reasonable to assume here that the addition of perlite and nano- $\mathrm{TiO}_{2}$ formed a structure with lower density due to the voids created that resulted in a decrease of apparent density and mechanical properties, alongside an increase in the resistance to salt decay.

With particular reference to the use of the developed mortars in the field of cultural heritage restoration, their compatibility has been demonstrated by meeting the requirements of UNI EN 998-1 for Renovation Mortar. In fact, all of the developed mortars, using hydraulic lime and metakaolin, are compatible and suitable with the materials used in traditional masonry, ensuring a good preservation and resistance to atmospheric conditions.

Future studies are still advisable to verify the adhesion properties of the mortars to various substrates and the methods of application of materials.

Author Contributions: Conceptualization, F.F. and P.-N.M.; methodology, F.F., P.-N.M., and D.K.; software, D.K. and K.G.; validation, S.G., R.M., R.B., M.T.E., M.M., K.K., K.G.; formal analysis, S.G., R.M., R.B., M.T.E., M.M., K.K., K.G.; investigation, S.G., R.M., R.B., M.T.E., M.M., K.K., P.D., A.M.L.; data curation, F.F., P.-N.M., and D.K.; writing—original draft preparation, F.F., P.-N.M., K.K.; writing—review and editing, F.F. and P.-N.M.; visualization F.F. and P.-N.M.; supervision, F.F. and P.-N.M.; project administration, F.F. and P.-N.M.; funding acquisition, F.F. All authors have read and agreed to the published version of the manuscript.

Funding: This research was funded by IEMEST, in the framework of the collaboration between MaCHMoB-Lab of Materials for Cultural Heritage and Modern Building at the Technical University of Crete and the Institute I.E.ME.S.T. and the scholarships' project entitled "Sperimentazione di malte innovative ad alta efficienza energetica con proprietà fotocatalitiche".

Acknowledgments: The authors would like to thank Stelios Mavrigiannakis, Technical Staf of Lab of Rock Engineering, for his excellent scientific and technical support for mechanical tests.

Conflicts of Interest: The authors declare no conflict of interest.

\section{References}

1. Pearlmutter, D.; Theochari, D.; Nehls, T.; Pinho, P.; Piro, P.; Korolova, A.; Papaefthimiou, S.; Mateo, M.C.G.; Calheiros, C.; Zluwa, I.; et al. Enhancing the circular economy with nature-based solutions in the built urban environment: Green building materials, systems and sites. Blue-Green Syst. 2019, 2, 46-72. [CrossRef]

2. European Union 2015 towards an EU Research and Innovation Policy Agenda for Nature-Based Solutions \& Re-Naturing Cities Final Report of the Horizon 2020 Expert Group on Nature-Based Solutions and Re-Naturing Cities. Available online: https://op.europa.eu/it/publication-detail/-/publication/fb117980-d5aa46df-8edc-af367cddc202 (accessed on 7 June 2020).

3. IUCN Commission on Ecosystem Management 2019 Nature-Based Solutions. Available online: https://www. iucn.org/commissions/commission-ecosystem-management/our-work/nature-based-solutions (accessed on 9 September 2020).

4. Lazzarini, L.; Laurenzi, T.M. Restauro Della Pietra; CEDAM: Padova, Italy, 1986.

5. Zehnder, K.; Arnold, A. Crystal growth in salt efflorescence. J. Cryst. Growth 1989, 97, 513-521. [CrossRef]

6. Zedef, V.; Kocak, K.; Doyen, A.; Ozsen, H.; Kekec, B. Effect of salt crystallization on stones of historical buildings and monuments, Konya, Central Turkey. Build. Environ. 2007, 42, 1453-1457. [CrossRef]

7. Scherer, G.W. Stress from crystallization of salt. Cem. Concr. Res. 2004, 34, 1613-1624. [CrossRef]

8. Ruiz-Agudo, E.; Mees, F.; Jacobs, P.; Rodriguez-Navarro, C. The role of saline solution properties on porous limestone salt weathering by magnesium and sodium sulfates. Environ. Earth Sci. 2006, 52, $269-281$. [CrossRef]

9. Benavente, D.; Martínez-Martínez, J.; Cueto, N.; Garcia-Del-Cura, M.A. Salt weathering in dual-porosity building dolostones. Eng. Geol. 2007, 56, 729-740. [CrossRef]

10. Benavente, D. Why Pore Size Is Important in the Deterioration of Porous Stones Used in the Built Heritage. Rev. Soc. Mineral. 2011, 15, 41-42.

11. Andriani, G.; Walsh, N. The effects of wetting and drying, and marine salt crystallization on calcarenite rocks used as building material in historic monuments. Geol. Soc. London Speéc. Publ. 2007, 44, 129-141. [CrossRef] 
12. Barbera, G.; Barone, G.; Mazzoleni, P.; Scandurra, A. Laboratory measurement of ultrasound velocity during accelerated aging tests: Implication for the determination of limestone durability. Constr. Build. Mater. 2012, 36, 977-983. [CrossRef]

13. Yavuz, H.; Demirdag, S.; Caran, S. Thermal effect on the physical properties of carbonate rocks. Int. J. Rock Mech. Min. Sci. 2010, 47, 94-103. [CrossRef]

14. Cantisani, E.; Pecchioni, E.; Fratini, F.; Garzonio, C.A.; Malesani, P.; Molli, G. Thermal stress in the Apuan marbles: Relationship between microstructure and petrophysical characteristics. Int. J. Rock Mech. Min. Sci. 2009, 46, 128-137. [CrossRef]

15. Sáez-Pérez, M.; Rodríguez-Gordillo, J. Structural and compositional anisotropy in Macael marble (Spain) by ultrasonic, XRD and optical microscopy methods. Constr. Build. Mater. 2009, 23, 21-26. [CrossRef]

16. Rodríguez-Gordillo, J.; Sáez-Pérez, M. Effects of thermal changes on Macael marble: Experimental study. Constr. Build. Mater. 2006, 20, 355-365. [CrossRef]

17. Andriani, G.; Germinario, L. Thermal decay of carbonate dimension stones: Fabric, physical and mechanical changes. Environ. Earth Sci. 2014, 72, 2523-2539. [CrossRef]

18. Siegesmund, S.; Ullemeyer, K.; Weiss, T.; Tschegg, E.K. Physical weathering of marbles caused by anisotropic thermal expansion. Acta Diabetol. 2000, 89, 170-182. [CrossRef]

19. Fernandez, F.; Germinario, S. Alteration and deterioration of natural stone materials: Artificial aging as a tool of knowledge. Conserv. Valorization Cult. Herit. 2017, 10, 324-333.

20. Ozcelik, Y.; Careddu, N.; Yilmazkaya, E. The effects of freeze-thaw cycles on the gloss values of polished stone surfaces. Cold Reg. Sci. Technol. 2012, 82, 49-55. [CrossRef]

21. Pacheco-Torgal, F; Jalali, S. Nanotechnology: Advantages and drawbacks in the field of construction and building materials. Constr. Build. Mater. 2011, 82, 49-55. [CrossRef]

22. Theodoridou, M.; Charalambous, E.; Maravelaki, P.-N.; Ioannou, I. Amelioration of crushed brick-lime composites using nano-additives. Cem. Concr. Compos. 2016, 68, 77-87. [CrossRef]

23. Maravelaki, N.; Kapridaki, C.; Lionakis, E.; Verganelaki, A. Improvement of properties of hydraulic mortars with addition of nano-titania. In Adhesives Mechanical Properties, Technologies and Economic Importance; Dario, C., Ed.; Nova Science Publishers, Inc.: New York, NY, USA, 2014; pp. 79-92.

24. Sierra-Fernandez, A.; De La Rosa-García, S.C.; Gomez-Villalba, L.S.; Gómez-Cornelio, S.; Rabanal, M.E.; Fort, R.; Quintana, P.; Rosa-García, S.D.C.D.L. Synthesis, Photocatalytic, and Antifungal Properties of $\mathrm{MgO}, \mathrm{ZnO}$ and $\mathrm{Zn} / \mathrm{Mg}$ Oxide Nanoparticles for the Protection of Calcareous Stone Heritage. ACS Appl. Mater. Interfaces 2017, 9, 24873-24886. [CrossRef]

25. Nicolás-Pérez, M.; Kuchling, F.; Letelier, J.; Polvillo, R.; Wittbrodt, J.; Martinez-Morales, J.-R. Analysis of cellular behavior and cytoskeletal dynamics reveal a constriction mechanism driving optic cup morphogenesis. Elife 2016, 5, e15797. [CrossRef] [PubMed]

26. Gherardi, F.; Goidanich, S.; Dal Santo, V.; Toniolo, L. Layered Nano-TiO 2 Based Treatments for the Maintenance of Natural Stones in Historical Architecture. Angew. Chem. Int. Ed. Engl. 2018, 57, 7360-7363. [CrossRef] [PubMed]

27. Kapridaki, C.; Verganelaki, A.; Dimitriadou, P.; Maravelaki, P.-N. Conservation of Monuments by a Three-Layered Compatible Treatment of TEOS-Nano-Calcium Oxalate Consolidant and TEOS-PDMS-TiO 2 Hydrophobic/Photoactive Hybrid Nanomaterials. Material 2018, 11, 684. [CrossRef] [PubMed]

28. Kapridaki, C.; Xynidis, N.; Vazgiouraki, E.; Kallithrakas-Kontos, N.; Maravelaki, P.-N. Characterization of Photoactive $\mathrm{Fe}_{-} \mathrm{TiO}_{2}$ Lime Coatings for Building Protection: The Role of Iron Content. Material 2019, 12, 1847. [CrossRef]

29. Daniyal; Akhtar, S.; Azam, A. Effect of nano- $\mathrm{TiO}_{2}$ on the properties of cementitious composites under different exposure environments. J. Mater. Res. Technol. 2019, 8, 6158-6172. [CrossRef]

30. Ng, D.S.; Paul, S.C.; Anggraini, V.; Kong, S.Y.; Qureshi, T.S.; Rodriguez, C.R.; Liu, Q.-F.; Šavija, B. Influence of $\mathrm{SiO}_{2}, \mathrm{TiO}_{2}$ and $\mathrm{Fe}_{2} \mathrm{O}_{3}$ nanoparticles on the properties of fly ash blended cement mortars. Constr. Build. Mater. 2020, 258, 119627. [CrossRef]

31. Maury-Ramirez, A.; Demeestere, K.; De Belie, N. Photocatalytic activity of titanium dioxide nanoparticle coatings applied on autoclaved aerated concrete: Effect of weathering on coating physical characteristics and gaseous toluene removal. J. Hazard. Mater. 2012, 212, 218-225. [CrossRef]

32. Hassan, M.; Dylla, H.; Mohammad, L.N.; Rupnow, T. Evaluation of the durability of titanium dioxide photocatalyst coating for concrete pavement. Constr. Build. Mater. 2010, 24, 1456-1461. [CrossRef] 
33. Diamanti, M.V.; Brunella, M.F.; Pedeferri, M.P.; Pirotta, C.; Manzocchi, P.; Curtoni, S. Selfcleaning and Antipolluting Properties of $\mathrm{TiO}_{2}$-Containing Cementitious Materials; NSTI Nanotech: Santa Clara, CA, USA, 2007; pp. 1-5.

34. Zhang, S.-H.; Tanadi, D.; Li, W. Effect of photocatalyst $\mathrm{TiO}_{2}$ on workability, strength and self-cleaning efficiency of mortars for applications in tropical environment. In Proceedings of the 35th Conference our world Concrete Structure 2010, Singapore, 25-27 August 2010.

35. Midtdal, K.; Jelle, B.P. Self-cleaning glazing products: A state-of-the-art review and future research pathways. Sol. Energy Mater. Sol. Cells 2008, 43, 2124-2131. [CrossRef]

36. Maggos, T.; Plassais, A.; Bartzis, J.G.; Vasilakos, C.; Moussiopoulos, N.; Bonafous, L. Photocatalytic degradation of $\mathrm{NOx}$ in a pilot street canyon configuration using $\mathrm{TiO}_{2}$-mortar panels. Environ. Monit. Assess. 2008, 136, 35-44. [CrossRef]

37. UNI EN 1015-10, Metodi di Prova per Malte per Opere Murarie-Parte 10: Determinazione Della Massa Volumica Apparente Della Malta Indurita Essiccata; UNI—Ente Italiano di Normazione: Milan, Italy, 2007.

38. UNI EN 12087, Isolanti Termici per Edilizia-Determinazione Dell'assorbimento D'acqua a Lungo Termine: Prova Attraverso Immersione; UNI-Ente Italiano di Normazione: Milan, Italy, 2013.

39. UNI EN 15803, Conservazione dei Beni Culturali-Metodi di Prova-Determinazione Della Permeabilità al Vapore $D^{\prime}$ acqua (dp); UNI-Ente Italiano di Normazione: Milan, Italy, 2010.

40. ASTM E903-96, Standard Test Method for Solar Absorptance, Reflectance, and Transmittance of Materials Using Integrating Spheres; ASTM International: West Conshohocken, PA, USA, 2005.

41. UNI EN 1015-11, Metodi di Prova per Malte per Opere Murarie-Parte 11: Determinazione Della Resistenza a Flessione e a Compressione Della Malta Indurita; UNI—Ente Italiano di Normazione: Milan, Italy, 2019.

42. Maravelaki-Kalaitzaki, P.; Agioutantis, Z.; Lionakis, E.; Stavroulaki, M.; Perdikatsis, V. Physico-chemical and mechanical characterization of hydraulic mortars containing nano-titania for restoration applications. Cem. Concr. Compos. 2013, 36, 33-41. [CrossRef]

43. Larsen, P.K. Climatic Protection of Historical Vaults with Lime-perlite Mortar. Stud. Conserv. 2020, 1-6. [CrossRef]

44. Rashad, A.M. A comprehensive overview about recycling rubber as fine aggregate replacement in traditional cementitious materials. Int. J. Sustain. Built Environ. 2016, 5, 46-82. [CrossRef]

45. Kolokotsa, D.; Maravelaki, P.-N.; Papantoniou, S.; Vangeloglou, E.; Saliari, M.; Karlessi, T.; Santamouris, M. Development and analysis of mineral based coatings for buildings and urban structures. Sol. Energy 2012, 86, 1648-1659. [CrossRef]

46. Gobakis, K.; Kolokotsa, D.; Maravelaki, P.-N.; Perdikatsis, V.; Santamouris, M. Development and analysis of advanced inorganic coatings for buildings and urban structures. Energy Build. 2015, 89, 196-205. [CrossRef]

47. Valentini, F.; Morandini, F.; Bergamo, M.; Dorigato, A. Development of eco-sustainable plasters with thermal energy storage capability. J. Appl. Phys. 2020, 128, 075103. [CrossRef]

48. Dénes, T.-O.; Tămaş-Gavrea, D.-R. Mechanical Properties of Lime Based Composites. Procedia Manuf. 2020, 46, 19-26. [CrossRef]

(C) 2020 by the authors. Licensee MDPI, Basel, Switzerland. This article is an open access article distributed under the terms and conditions of the Creative Commons Attribution (CC BY) license (http://creativecommons.org/licenses/by/4.0/). 